\title{
ANALISIS TRANSFORMASI EKONOMI SEKTOR PERTANIAN ANTAR PROVINSI DI PULAU KALIMANTAN
}

\section{Amak Priyatna, Dewi Rahayu, Saipudin}

Universitas Lambung Mangkurat, Banjarmasin, Indonesia

Email:priyatna.ama@gmail.com, dewirahayu@ulm.ac.id, saipudinsaif123@gmail.com

\begin{tabular}{l} 
INFO ARTIKEL \\
Diterima \\
28 November 2021 \\
Direvisi \\
15 Desember 2021 \\
Disetujui \\
1 Januari 2022 \\
\hline
\end{tabular}

Kata Kunci:

Transformasi;

Sektor; Pertanian; Pertambangan; Basis

\begin{abstract}
ABSTRAK
Arah transformasi menurunkan ketergantungan sumber daya alam dengan bergeser ke arah industri dan jasa sehingga perlu diketahui pola transformasi terkait perubahan laju pertumbuhan kontribusi dan daya saing. Sektor pertanian pada tahun 2020 kontribusinya 50-25\% dalam pembentuk PDRB tersebar di 44 kabupaten dari 51 kabupaten di pulau kalimantan. Penelitian ini menggunakan kualntitatif Data sekunder PDRB Provinsi di Pulau Kalimantan 2010-2020 sebagai rujukan penelitian. Analisis Location Quotien dan Shift-Share digunakan dalam penelitian ini dan hasilnya sebagai bahan pertimbangan terukur perencanaan pembangunan daerah. Hasil menunjukan sektor pertanian mempertahankan kontribusi positif dan subsektor memiliki daya saing yaitu Perkebunan, Holtikultura, Perikanan dan Peternakan. Telah terjadi transformasi pertanian ditandai kontribusi fluktuasi dan penurunan laju pertumbuhan kedepannya perlu diantisipasi. Percepatan transformasi melalui kebijakan hilirisasi komoditas pertanian namun terhambat regenerasi sumber daya manusia kompeten dan lambatnya penerapan teknologi pertanian terintegrasi.
\end{abstract}

\begin{abstract}
The direction of transformation decreases the dependence of natural resources by shifting towards industry and services so that it is necessary to know the pattern of transformation related to changes in the growth rate of contribution and competitiveness. The agricultural sector in 2020 contributed 50-25\% in the formation of PDRB spread across 44 districts from 51 districts on the island of Kalimantan. Secondary data of Provincial PDRB on Kalimantan Island 2010-2020 as a reference for research. Location Quotien and Shift-Share analysis was used in this study and the results were measurable considerations of regional development planning. The results showed the agricultural sector maintained a positive contribution and the subsectors had competitiveness namely Plantation, Horticulture, Fisheries and Livestock. There has been a transformation of agriculture marked by the contribution of fluctuations and decreases in the rate of growth in
\end{abstract}

Keywords: Transformation; the policy of downstreaming agricultural commodities but hampered Sector; Agriculture; by the regeneration of competent human resources and the slow Mining; Base

$\begin{array}{lllll}\text { How to cite: } & \text { Priyatna, A, Dewi Rahayu, Saipudin (2022). Analisis Transformasi Ekonomi Sektor Pertanian Antar } \\ & \text { Provinsi Di Pulau Kalimantan, } & \text { Jurnal } & \text { Syntax } & \text { Transformation, } \\ & \text { https://doi.org/10.46799/jst.v3i1.489 } & \\ \text { E-ISSN: } & 2721-2769 & & \\ \text { Published by: } & \text { Ridwan Institute }\end{array}$




\section{Pendahuluan}

Sektor Pertanian menopang ketahanan pangan, pendapatan ekspor dan pembangunan pedesaan. Pembangunan pertanian tetap menjadi salah satu alat paling efektif untuk mengakhiri kemiskinan ekstrem, meningkatkan kemakmuran bersama, dan memberi makan 9,7 miliar orang yang diproyeksikan pada tahun 2050. Untuk memenuhi permintaan, pertanian pada tahun 2050 perlu menghasilkan hampir 50 persen lebih banyak makanan, pakan, dan bahan bakar nabati dibandingkan tahun 2012 (FAO, 2018).

Fenomena krisis ekonomi melanda dunia untuk pertumbuhan PDRB sektor pertanian mengalami pertumbuhan poistif dan stagnan, regenerasi petani dan nelayan mengalami fluktuatif dikarenakan nilai tukar petani semakin tertekan, tingkat pertumbuhan produksi pertanian menurun karena perubahan iklim yang ekstim menyebabkan perubahan pola tanam dan teknologi di pulau kalimantan, anggaran belanja subsektor pertanian, kehutanan dan perikanan terus menurun karena perlambatan ekonomi. produktivitas pertanian terus di bawah ekspektasi. Fenomena perubahan iklim yang terjadi di pulau kalimantan menyebabkan pertumbuhan produksi yang lambat dan fluktuasi tahunan yang tajam dalam output terus menjadi masalah kronis pembangunan sector pertanian yang menjadi salah satu penyebab meningkatnya kemiskinan dan kerawanan pangan. Kemajuan yang signifikan dalam mendorong pertumbuhan ekonomi, mengurangi kemiskinan dan meningkatkan ketahanan pangan tidak dapat dicapai tanpa secara sadar mengembangkan lebih penuh kapasitas produktif sektor pertanian (FAO, 2018).

Sektor pertanian sebagai penggerak perekonomian sebanyak $82 \%$ dari 75.436 desa yang ada di Indonesia masih perlu akselerasi regenerasi petani. Regenerasi petani ini mutlak diperlukan di tengah struktur demografi petani Indonesia yang rata-rata berusia 47 tahun. Jika tidak diantisipasi dari sekarang, maka kita akan mengalami krisis petani dalam kurun waktu 10-15 tahun ke depan (Arif, S., \& Helmi, 2021).

Transformasi Ekonomi ditempatkan didepan untuk menampilkan berbagai analisa jangka panjang dan lintas sektor (longee duree). Perencanaan kebijakan publik dan ekonomi membutuhkan target jangka panjang (indicative planning) sehingga berbagai kegiatan dan program mempunyai efek akumulasi dan tidak zigzag terlalu jauh (Budisusila, 2021). Pertumbuhan ekonomi yang terjadi secara terus menerus serta sektor ekonomi yang tumbuh lebih cepat dari sektorsektor lainnya sehingga terjadi transformasi ekonomi. Pembangunan sektor pertanian ditandai kontribusi sektor pertanian yang besar, namun dalam perkembangan selanjutnya kontribusi sektor industri meningkat sebaliknya kontribusi sektor pertanian menurun, dan kemudian setelah perekonomian mencapai tingkat yang cukup tinggi peranan sektor jasa meningkat dan menjadi komponen utama dari perekonomian. Data dari 56 kabupaten/kota pada tahun 20102016 bahwa mayoritas wilayah di Pulau Kalimantan tergolong dalam daerah berkembang cepat (Pratiwi, 2021). Berdasarkan Arthur Lewis menjelaskan dalam (Hasan et al., 2020) bahwa transformasi ekonomi merupakan perubahan struktur ekonomi dari berpola pertanian subsisten tradisional menjadi pola modern berorientasi kehidupan perkotaan. Persentase penduduk miskin mengalami penurunan setiap tahunnya, pada tahun 2010 jumlah penduduk miskin sebesar $11,96 \%$ jumlah tersebut mengalami penurunan menjadi $10,12 \%$ pada tahun 2017. Namun jumlah penduduk miskin sebagian besar berada di pedesaan, pada tahun 2017 penduduk miskin di perdesaan $61,36 \%$ dan di perkotaan $38,6 \%$ (BPS, 2019). Sektor pertanian tradisional 
berbasis dipedesaan dengan produktivitas rendah dan sektor industri modern memiliki produktivitas tinggi (Todaro \& Smith, 2003a). Sektor pertanian memiliki kontribusi ekonomi sebesar 2,8 \% dari ekonomi global, penyerapan tenaga kerja sector pertanian diperkirakan $19 \%$ sekitar 1,3 miliar (Alston \& Pardey, 2014). Dalam menentukan daya saing produk pertanian harus melihat keunggulan- keunggulan seperti, upah buruh murah dan Sumber Daya Alam yang melimpah. Menurut (Safriansyah, 2010) Tren pembangunan saat ini terjadi penurunan kontribusi sektor pertanian terhadap produk domestik bruto dan terjadi peningkatan kontribusi pada sektor non-pertania (Briones $\&$ Felipe, 2013) (Pratiwi, 2021).

Menurut (Kuncoro \& Idris, 2015) hasil pembangunan di Pulau Kalimantan belum mampu meningkatkan kesejahteraan masyarakatnya, sebagaimana tercermin dari masih banyaknya keluarga miskin, pengangguran, dan meningkatnya ketimpangan antardaerah. Hal ini diperkuat dengan semakin menurunnya laju pertumbuhan ekonomi dan kontribusi PDRB Pulau Kalimantan terhadap PDB nasional

Kontribusi Sektor pertanian di pulau Kalimantan masih sangat diandalkan oleh pemerintah daerah hal ini memberikan dampak baik secara langsung maupun tidak langsung terhadap berbagai komoditas lainnya yang juga mendukung kontribusi terhadap PDRB. Berdasarkan RPJM tahun 2015 - 2019 bidang pangan dan pertanian guna meningkatkan daya saing produkproduk pertanian dilakukan melalui peningkatkan kemampuan petani, peningkatan kelembagaan, peningkatan produktivitas, peningkatan produksi, dan pendekatan klaster. kebijakan yang harus diambil untuk mengatasi masalah kemiskinan adalah dengan mengembangkan sektor pertanian. Peningkatan pendapatan per kapita harus mencerminkan peningkatan pendapatan masyarakat miskin, yang biasanya berada di pedesaan dan sebagian besar bekerja di sektor pertanian (Ardiansyah et al., 2020). Rumusan penelitian ini untuk mengetahui peranan sektor pertanian terhadap PDRB Provinsi di pulau Kalimantan. Tujuan penelitian ini Menganalisis perubahan laju pertumbuhan dan kontribusi subsektor pertanian pulau Kalimantan terhadap perekonomian daerah antara regional dan nasional.mengetahui transformasi ekonomi sektor pertanian di pulau Kalimantan periode tahun 2013-2020 melalui pendekatan LQ dan DLQ, menganalisis apakah tranformasi ekonomi terjadi perubahan peranan pada masingmasing sub sektor pertanian dalam membentuk PDRB antar provinsi di Pulau Kalimantan serta menganalisis faktor yang berpengaruh terhadap kemajuan transformasi ekonomi sektor pertanian hasil penelitian digunakan memperkuat data dasar perencanaan dalam mengakselerasi kinerja program peningkatan ekonomi subsektor pertanian di wilayah yang mempunyai karakteristik yang hampir mirip dan bahan pertimbangan dalam pengambilan kebijakan dalam menyusun perencanaan pembangunan sektor pertanian dan pertambangan secara lebih terpadu dan terukur di pulau Kalimantan.

\section{Metode Penelitian}

Penelitian ini menggunakan metode kuantitatif (Sugiyono, 2013). Data menggunakan data PDRB antar Provinsi di Pulau Kalimantan Atas Dasar Harga Konstan menurut lapangan usaha sektor pertanian periode 2013-2020. Data penelitian diolah, dihitung, dikomplikasi, disajikan dalam bentuk tabulasi, grafik serta dideskripsikan data kontribusi dan laju pertumbuhan, analisis Location Quotient (LQ) untuk mengidentifikasi sektor basis dan non basis analisis Dynamic Location Quotient (DLQ), untuk mengidentifikasi pergeseran atau perubahan struktur ekonomi sektor pertanian yang ada di Pulau Kalimantan, serta 
mengunakan analisis kuantitatif untuk melihat pola transformasi ekonomi yang telah dilakukan untuk meningkatkan pertumbuhan sektor pertanian.

\section{Hasil dan Pembahasan}

Pertumbuhan ekonomi sebagai sebuah proses peningkatan output dari waktu ke waktu, menjadi indikator penting dalam mengukur keberhasilan pembangunan suatu negara (Todaro \& Smith, 2003a). Kinerja ekonomi Pulau Kalimantan secara umum membaik dan kegiatan perekonomiannya semakin meningkat. Hal ini terlihat dari nilai PDRB ADHK migas dan non migas seluruh provinsi di Pulau Kalimantan (kecuali Provinsi Kalimantan Timur) yang cenderung meningkat setiap tahun dan pertumbuhannya positif. Walaupun perekonomian wilayah Kalimantan cukup baik, namun hasil pembangunan di Pulau Kalimantan belum mampu meningkatkan kesejahteraan masyarakatnya.

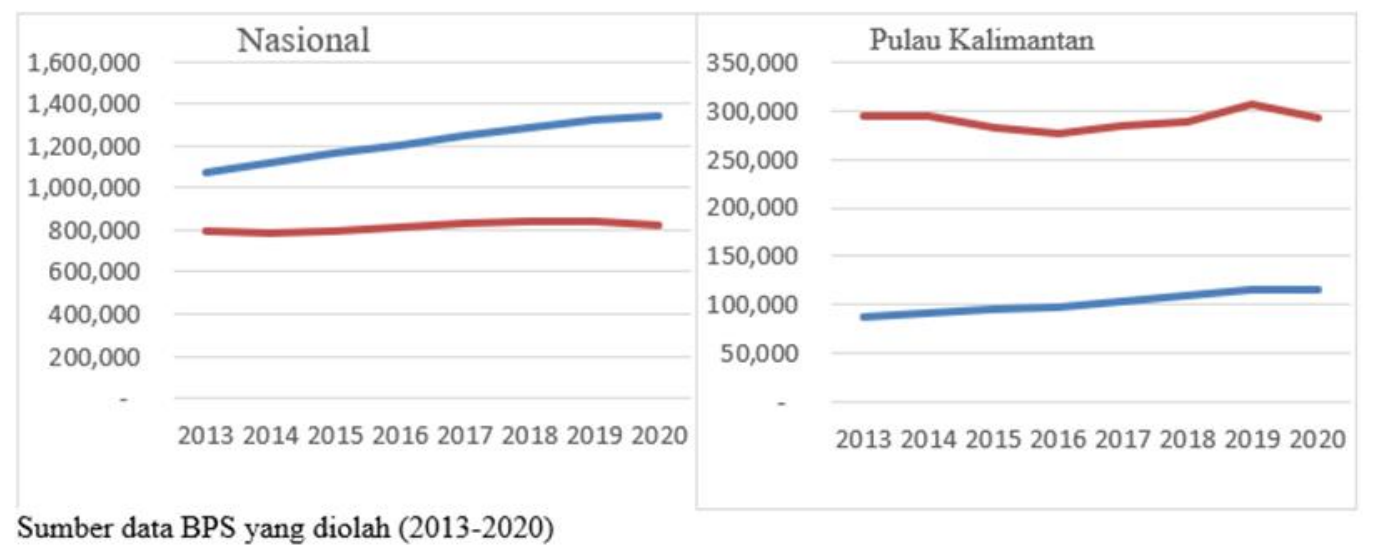

Gambar 1

Perbandingan PDRB Nasional Dan Gabungan Antara Propinsi PDRB Pulau Kalimantan Untuk Sektor Pertanian Dan Pertambangan

Dari grafik di atas dapat dijelaskan bahwa pola pertumbuhan pertanian mengalami peningkatan progresif dengan secara nasional namun pada pembentuk PDRB pulau kalimantan sektor pertanian mengalami pertumbuhan yang positif tiap tahunnya. Pulau kalimantan menghasilkan komoditi pertanian dan bahan pangan yang melimpah serta menyerap banyak tenaga kerja. Namun saat ini pulau kalimantan masih mendatangkan kebutuhan bahan pangan dari pulau laui misalnya kedelai, gula, garam dan gandum Berdasarkan PDB maupun penyerapan tenaga kerja telah terjadi transformasi struktur ekonomi dari sektor primer ke sektor tersier. Transformasi struktur ekonomi tersebut diikuti oleh mobilitas pekerja dari sektor primer ke sektor sekunder (Tajuddin et al., 2020). 


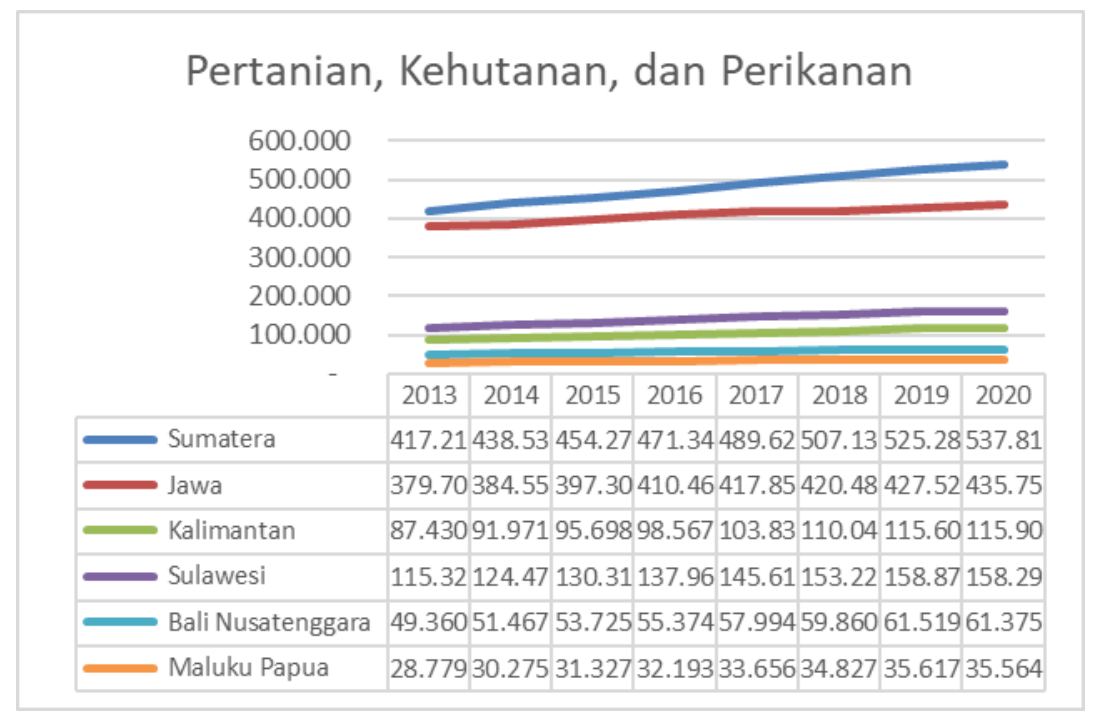

Gambar 2

Perbandingan PDRB Nasional Dan Gabungan Antara Propinsi PDRB Pulau Kalimantan Untuk Sektor Pertanian Dan Pertambangan

Dari grafik diatas pertumbuhan sektor pertanian, kehutanan dan perikanan antara pulau di indonesia pulau kalimantan berkontribusi secara nasional pada urutan ke 4 sehingga sektor pertanian dalam jangka panjang memiliki hubungan signifikan terhadap kemiskinan, Pendapatan per kapita pertanian memiliki hubungan positif dengan kemiskinan di Indonesia sehingga kebijakan yang harus dilaksanakan untuk mengatasi masalah kemiskinan adalah dengan mengembangkan sektor pertanian. kontribusi sektor berbasis sumber daya alam batubara mendominasi perekonomian pulau kalimantan kecuali propinsi kalimantan barat dan kalimantan tengah sektor pertanian diatas sektor pertambangan. Dari sisi andil terhadap ekonomi, aktivitas pertambangan masih lebih tinggi dibanding pertanian pemerintah daerah sebagai regulator pengelolaan sumberdaya alam masih ketergantungan terhadap sektor pertambangan yang dimilikinya. Jika dilihat dari perbandingannya terhadap Produk Domestik Regional Bruto (PDRB), sektor pertanian, kontribusinya hanya berkisar 15 persen terhadap total ekonomi kalimantan. Sehingga dapat dikatakan bahwa ekonomi pulau kalimantan berkaitan erat dengan kondisi produktivitas pertambangannya. Menurut (Abidin, 2015) gambaran tersebut sejalan dengan grafik perbandingan pertumbuhan sektor pertanian dan pertambangan di pulau kalimantan. 


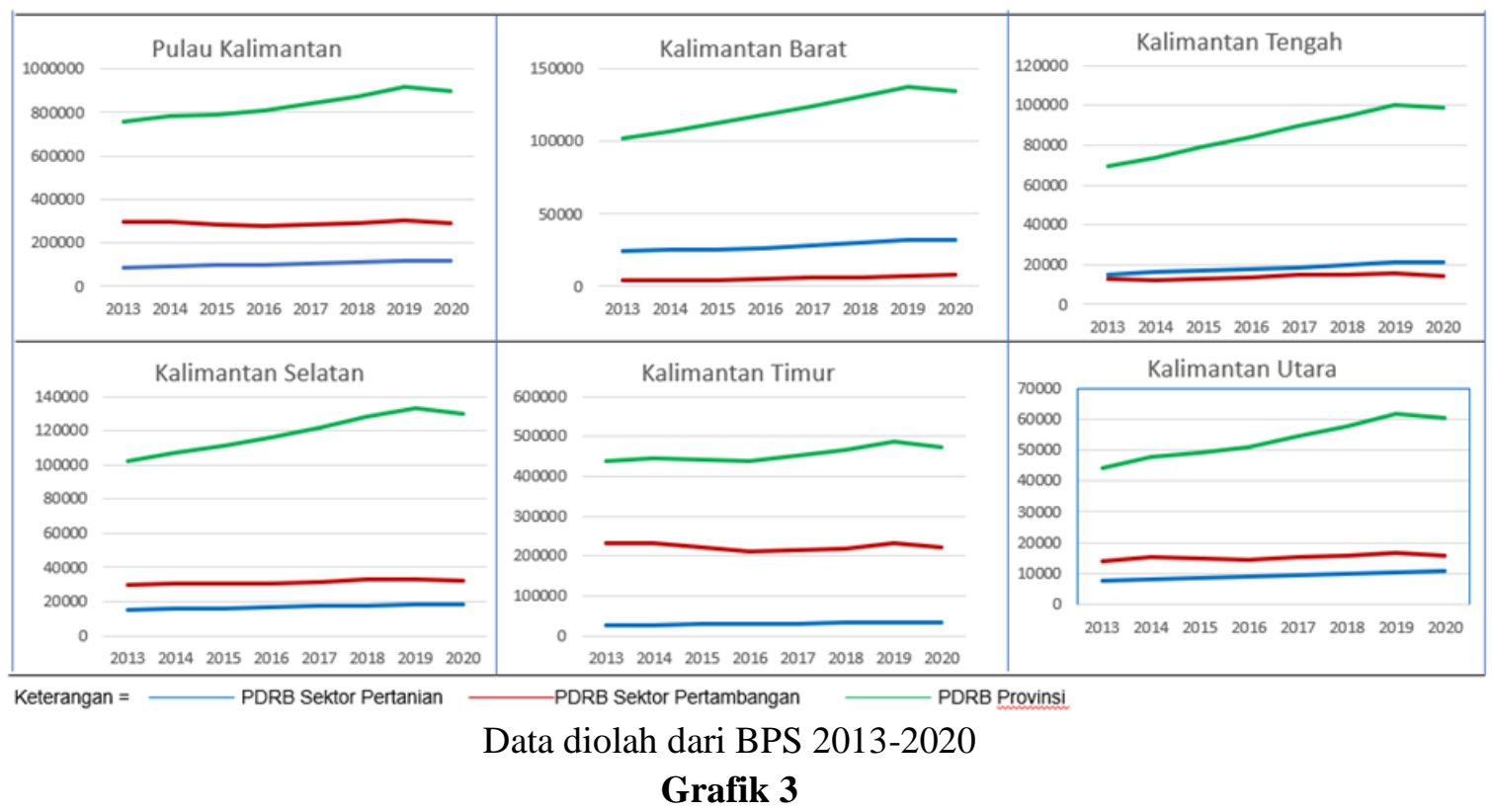

Perbandingan PDRB Nasional Dan Gabungan Antara Propinsi PDRB pulau Kalimantan Untuk Sektor Pertanian Dan Pertambangan

Dari analisis kontribusi menunjukkan bahwa mengalami transformasi ekonomi dari sector potensial ke sektor yang progresif. Sector pertanian, kehutanan dan perikanan merupakan sektor potensial dan memiliki kontribusi terbesar terhadap PDRB pulau kalimantan tetapi tergolong sector ekonomi yang bergerak lambat, keunggulan kompetitif yang negatif atau tidak memiliki daya saing tinggi, dan tergolong sector perekonomian yang non progresif. Hal ini didukung oleh teori yang dikemukakan oleh Lewis dan Chenery (Todaro \& Smith, 2003b).

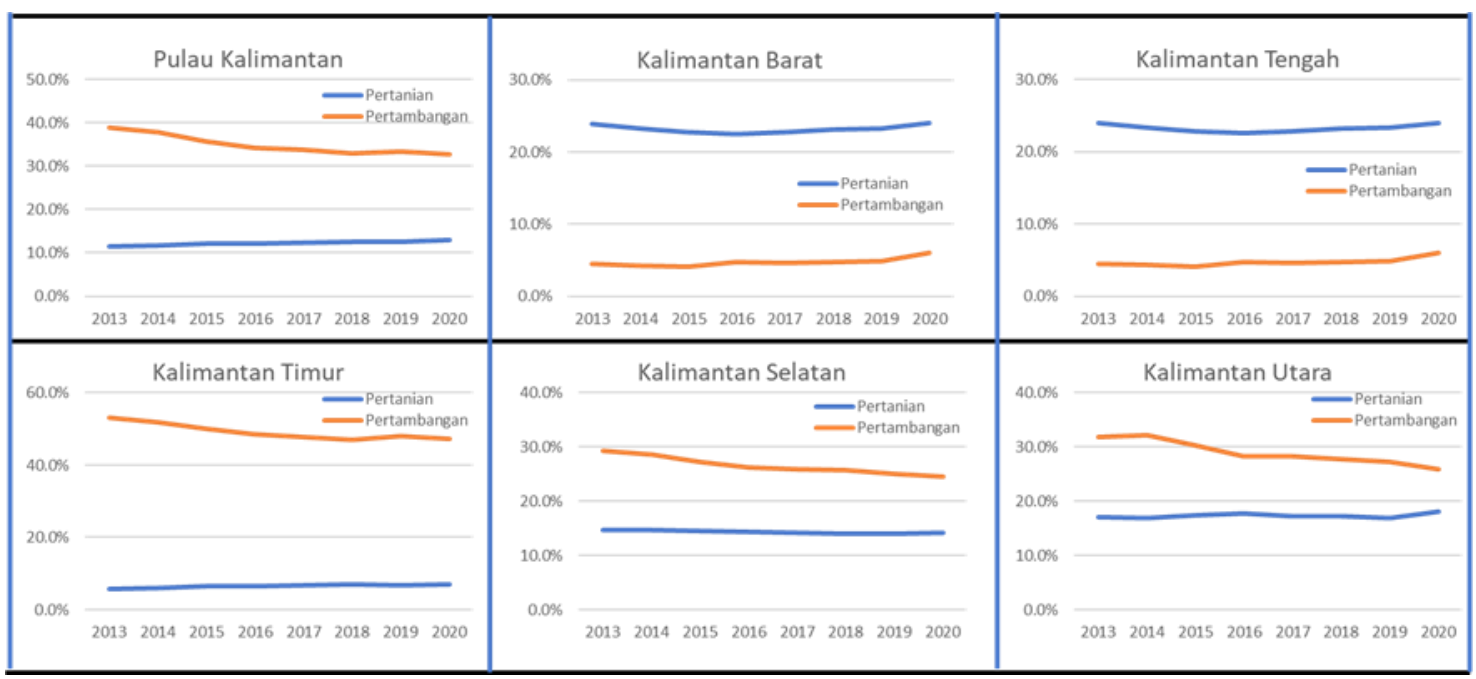

Data diolah dari BPS 2013-2020

Grafik 4

Kontribusi Sektor Pertanian Dan Sektor Pertambangan ntaar Propinsi di Pulau Kalimantan 
Dari data grafik perbandingan antara provinsi di pulau kalimantan hasil analisis kontribusi pada provinsi yang mengandalakan sektor pertambangan mangalami penurunan kontribusi pembentuk PDRB sedangkan sektor pertanian terjadi trend peningkatan yang belum maksimal. Tren pembangunan modern ditandai dengan menurunnya kontribusi sektor pertanian terhadap PDB (produk domestik bruto), sebagai akibat dari meningkatnya kontribusi sektor nonpertanian. Sehingga strategi pembangunan yang sering diterapkan adalah dengan meningkatkan peran sektor modern (industri dan jasa) yang memiliki tingkat produktivitas yang tinggi. Sektor pertanian yang produktivitasnya rendah seringkali luput dari strategi pembangunan, padahal sektor pertanian menjadi mata pencaharian sebagian masyarakat miskin yang berada di pedesaan (Ardiansyah et al., 2020).
Menurut (Safriansyah, 2010) ketimpangan antarwilayah di pulau kalimantan disebabkan oleh perbedaan kandungan sumber daya alam dan kondisi demografi masing-masing wilayah, sehingga kemampuan suatu daerah dalam mendorong proses pembangunan menjadi berbeda pula. Perbedaan kekayaan daerah menimbulkan adanya wilayah maju (developed region) dan wilayah terbelakang (underdeveloped region). Ketimpangan regional di pulau kalimantan terjadi karena pemerintah pusat menguasai dan mengendalikan hampir sebagian besar pendapatan daerah yang ditetapkan sebagai penerimaan negara. Arus investasi Pembangunan pertanian masih terpusat di Kawasan Indonesia Barat khususnya di Pulau Jawa. Dilihat laju pertumbuhan terjadi pola yang berbeda antar profinsi di pulau kalimantan diantaranya sektor pertanian mengalami tekanan laju pertumbuhan di tahun 2017 hingga tahun 2019.

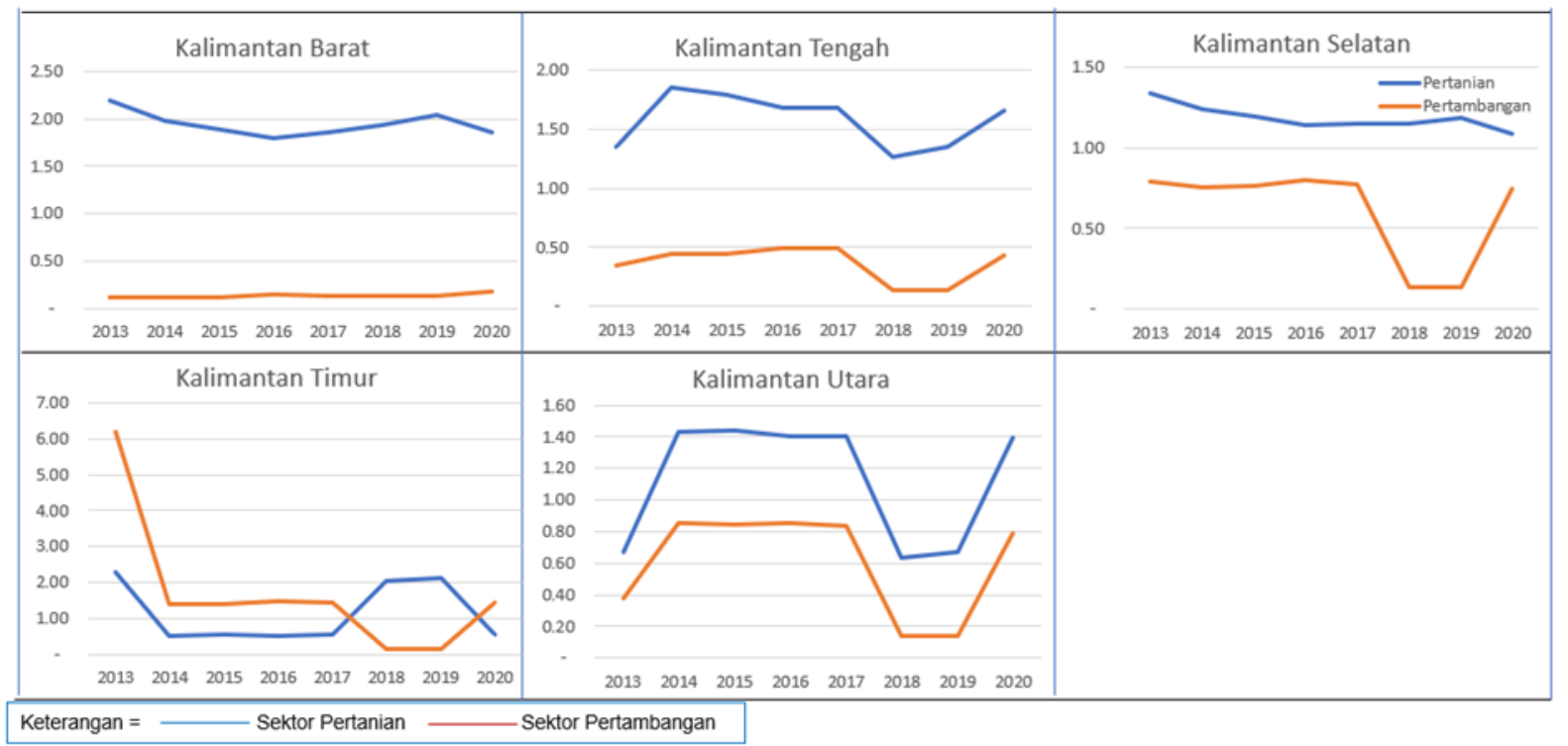

Gambar 5

Pola Perkembangan fluktuasi laju pertumbuhan sektor petanian antar propinsi di Pulau Kalimantan

1. Penilaian Location Quotient

Location Quotient adalah perbandingan peran sektor suatu daerah terhadap peran sektor secara nasional. Analisis ini sebagai perbandingan regional dengan nasional agar diketahui sektor ekonomi pembentuk PDRB yang termasuk sektor basis dan non basis (De Fretes, 2017). Nilai LQ > 1 merupakan petunjuk bahwa wilayah tersebut surplus 
akan produk dan di suatu wilayah sektor ekonomi lebih dominan /basis dibandingkan sektor wilayah induknya tersebut. sedangkan, LQ $<1$ berarti peranan sektor tersebut lebih kecil di wilayah tersebut dibandingkan peranannya di wilayah induknya atau sektor non basis (Alhowaish et al., 2015) (Fattah \& Rahman, 2013). Metoda Location Quotient sebagai salah satu pendekatan model ekonomi basis, relevan dan dapat digunakan sebagai salah satu teknik untuk mengidentifikasi penyebaran komoditas pertanian. Dalam hal ini komoditas yang memiliki nilai LQ > 1 dianggap memiliki keunggulan komparatif karena tergolong basis. Komoditas pertanian yang tergolong basis dan memiliki sebaran wilayah paling luas menjadi salah satu indikator komoditas unggulan nasional,
Penilaian LQ merupakan indikator awal untuk melihat sektor ekonomi potensial (sektor basis) yang memiliki pengaruh pertumbuhan ekonomi serta sektor yang tidak berpotensial (non basis). Hasil analisis lq sektor yang memiliki LQ $>1$ antara lain sub sektor tanaman perkebunan, perikanan subsektor ini merupakan sector basis dan potensial yang dikembangkan sebagai penggerak perekonomian di pulau kalimantan kedepannya. subsektor pertanian untuk periode 2013-2020 merupakan basis unggulan berurutan sebagai berikut tanaman perkebunan, kehutanan dan penebangan kayu, subsector perikanan, Tanaman Pangan, Peternakan, Tanaman Holtikultura. Namun sector pertanian masih tetap mempertahankan konribusi positif untuk menyumbang besaran sector primer di Pulau Kalimantan.

Tabel 1

Nilai rata-rata Location Quotient Sektor Pertanian antar Propinsi di Pulau Kalimantan

\begin{tabular}{cccccccc}
\hline Prov & $\begin{array}{c}\text { Pertanian, } \\
\text { kehutanan, } \\
\text { dan } \\
\text { perikanan }\end{array}$ & $\begin{array}{c}\text { Petanian, } \\
\text { peikanan, } \\
\text { perkebunan } \\
\text { dan jasa } \\
\text { pertanian }\end{array}$ & $\begin{array}{c}\text { Kehutanan } \\
\text { dan } \\
\text { penebangan } \\
\text { kayu }\end{array}$ & Perikanan & $\begin{array}{c}\text { Tanaman } \\
\text { pangan }\end{array}$ & $\begin{array}{c}\text { Tanaman } \\
\text { holtikultura }\end{array}$ & $\begin{array}{c}\text { Tanaman } \\
\text { perkebunan } \\
\text { pertanian } \\
\text { dan } \\
\text { pemburuan }\end{array}$ \\
\hline Kalbar & 1.81 & 2.02 & 2.28 & 0.74 & 1.08 & 1.45 & 3.20 \\
\hline Kalteng & 1.66 & 1.83 & 1.81 & 0.88 & 1.61 & 0.37 & 1.51 \\
\hline Kalsel & 1.11 & 1.05 & 0.72 & 1.47 & 1.46 & 0.10 & 1.17 \\
\hline Kaltim & 0.51 & 0.42 & 1.63 & 0.59 & 0.07 & 0.23 & 0.92 \\
\hline Kaltara & 1,35 & 0.59 & 7.28 & 3.00 & 0.20 & 0.18 & 0.23 \\
\hline
\end{tabular}

Dari pola nilai lq di pulau kalimantan masing masing tempat bervariasi dan fluktuatif nilai disebabkan terganggunya produksi sektor pertanian karena perubahan iklim yang ekstrim terutama kekeringan dan banjir yang menyebabkan kontribusi sektor pertanian menyalami tekanan yang terlihan dimulai dari tahun 2017 hingga 2019. Penurunan peranan sektor pertanian diduga rendahnya pengetahuan petani atas akses informasi dan teknologi, kurangnya kepemilikan dan lemahnya akses modal baik modal kerja maupun investasi, semakin terbatasnya lahan yang dapat dipakai untuk bertani. Namun ditahun 2020 mengalami pertumbuhan PDRB yang disebabnya tingginya permintaan akan bahan baku minyak sawit untuk energi terbarukan dan membaiknya harga minyak sawit dilevel internasional, tingginya kebutuhan tanaman pangan, holtikultura dan pangan ikan dan hewani dalam masyarakat dalam menuhi kebutuhan pangan fungsional untuk peningkatan kesehatan dimasa pandemi 2019 hingga sekarang. 

Tabel 2

Peringkat Kemajuan Pembangunan Subsektor Pertanian di Pulau Kalimantan

\begin{tabular}{cccccccccc}
\hline Prov & $\begin{array}{c}\text { Pertanian, } \\
\text { kehutanan, } \\
\text { dan } \\
\text { perikanan }\end{array}$ & $\begin{array}{c}\text { Petanian, } \\
\text { peikanan, } \\
\text { perkebunan } \\
\text { dan jasa } \\
\text { pertanian }\end{array}$ & $\begin{array}{c}\text { Kehutanan } \\
\text { dan } \\
\text { penebangan } \\
\text { kayu }\end{array}$ & Perikanan & $\begin{array}{c}\text { Tanaman } \\
\text { pangan }\end{array}$ & $\begin{array}{c}\text { Tanaman } \\
\text { holtikultura }\end{array}$ & $\begin{array}{c}\text { Tanaman } \\
\text { perkebunan }\end{array}$ & $\begin{array}{c}\text { Peternakan } \\
\text { pertanian } \\
\text { dan } \\
\text { pemburuan }\end{array}$ \\
\hline 1 & Kalbar & Kalbar & Kaltara & Kaltara & Kalbar & Kalbar & Kalteng & Kalteng & Kalteng \\
\hline 2 & Kalteng & Kalteng & Kalbar & Kalsel & Kalteng & Kaltara & Kalbar & Kalbar & Kalbar \\
\hline 3 & Kaltara & Kaltara & Kalteng & Kalteng & Kalsel & Kalteng & Kalsel & Kalsel & Kalsel \\
\hline 4 & Kalsel & Kalsel & Kaltim & Kalbar & Kaltara & Kaltim & Kaltim & Kaltara & Kaltara \\
\hline 5 & Kaltim & Kaltim & Kalsel & Kaltim & Kaltim & Kalsel & Kaltara & Kaltim & Kaltim \\
\hline
\end{tabular}

Keterangan : Data yang diolah BPS 2013-2020

Berdasarkan identifikasi keunggulan kompetitif, sektor ekonomi unggulan pertanian provinsi Kalimantan barat dan Kalimantan tengah mendominasi unggulan di sector pertanian. sektor tanaman perkebunan dan kehutanan merupakan basis pembangunan sector pertanian disusul sub sector perikanan di Kalimantan utara dan Kalimantan selatan berpeluang dapat dikembangkan dan Kelola kedepannya, pulau Kalimantan luas perkebunan kelapa sawit terus meningkat perubahan penggunaan lahan untuk perluasan perkebunan tanaman komersial, menggantikan ekosistem alam termasuk hutan. Perdagangan internasional merupakan faktor penting dalam proses ini. Meningkatnya permintaan tanaman tertentu telah memicu ekspansi perkebunan dan deforestasi, serta mempengaruhi penggunaan lahan lokal (telekoneksi lahan). Ekspansi kelapa sawit adalah salah satu contoh telekoneksi darat yang paling menonjol (Yuniarti \& Sukarniati, 2021). Guna mendorong pertumbuhan ekonomi di masa depan diperlukan keterpaduan sektor basis dan sektor non basis. Sedangkan nilai Location Quotient $<1$ merupakan sektor yang kurang berpotensial untuk dikembangkan sector non basis sebagai penggerak perekonomian yaitu di propinsi kalimantan timur karena daerah ini masih mengandalkan, tetapi sector ini menunjang perkembangan sektor basis. Sektor mengalami perubahan selama proses pembangunan berlangsung mencakup pergeseran yang berangsurangsur dari sektor pertanian ke sektor non pertanian. Hal ini sejalan dengan teori pertumbuhan ekonomi modern yang menyatakan bahwa perubahan struktural dalam pertumbuhan ekonomi modern mencakup peralihan dari kegiatan pertanian ke nonpertanian, dari industry ke jasa, perubahan dalam skala unit-unit produktif, peralihan dari perusahaan perseorangan menjadi perusahaan berbadan hukum serta perubahan status kerja buruh (Jhingan, 2016).

2. Analisis Dynamic Location Quotient

$$
\text { Metode Dynamic Location }
$$

Quotient menganalisi perubahan posisi terhadap sektor pertanian dilakukan lebih menekankan pada proporsi laju pertumbuhan sector perekonomian (PDRB) dibandingkan sektor perekonomian Nasional. kedepannya sektor pertanian akan tetap akan menjadi basis atau terjadi reposisi menjadi non basis. Hasil analisisDynamic Location Quotient (DLQ) perekonomian antar Provinsi dipulau Kalimantan dapat dilihat pada tabel 3 
Tabel 3

Hasil Analisis Location Quotient (LQ) sektor pertanian di pulau Kalimantan

\begin{tabular}{|c|c|c|c|c|c|c|c|c|c|}
\hline DLQ & $\begin{array}{l}\text { Pertanian, } \\
\text { kehutanan, } \\
\text { dan } \\
\text { perikanan }\end{array}$ & $\begin{array}{c}\text { Petanian, } \\
\text { peikanan, } \\
\text { perkebunan } \\
\text { dan jasa } \\
\text { pertanian } \\
\end{array}$ & $\begin{array}{c}\text { Kehutanan } \\
\text { dan } \\
\text { penebangan } \\
\text { kayu }\end{array}$ & Perikanan & $\begin{array}{c}\text { Tanaman } \\
\text { pangan }\end{array}$ & $\begin{array}{c}\text { Tanaman } \\
\text { holtikultura }\end{array}$ & $\begin{array}{c}\text { Tanaman } \\
\text { perkebunan }\end{array}$ & Peternakan & $\begin{array}{c}\text { Jasa } \\
\text { pertanian } \\
\text { dan } \\
\text { pemburuan }\end{array}$ \\
\hline Kalbar & 1.01 & 1.01 & 1.05 & 1.01 & 1.15 & 1.02 & 1.01 & 1.01 & 1.02 \\
\hline Kalteng & 1.01 & 1.01 & 1.42 & 1.03 & 1.07 & 1.19 & 1.01 & 1.01 & 1.05 \\
\hline Kalsel & 1.00 & 1.01 & 1.01 & 1.01 & 1.05 & 1.01 & 1.01 & 1.01 & 1.01 \\
\hline Kaltim & 0.97 & 0.96 & 1.02 & 1.01 & 1.77 & 1.01 & 1.02 & 1.01 & 0.99 \\
\hline Kaltara & 1.00 & 1.47 & 1.03 & 1.02 & 1.63 & 1.07 & 1.02 & 1.01 & 1.00 \\
\hline
\end{tabular}

Hasil analisis Dynamic Location Quotient (DLQ) menunjukkan bahwa sektor pertanian tidak mengalami perubahan posisi karena memiliki nilai DLQ > 1 sehingga kedepan sektor pertanian masih tetap menjadi sektor basis yang dapat diunggulkan dan mempunyai daya saing yang tinggi dibandingkan sektor pertanian di pulau kalimantan terhadap nasional. Globalisasi dan perubahan cepat kemajuan teknologi yang terus terjadi memberikan dampak terhadap perubahan pembangunan sektor pertanian. Berhasilnya pembangunan suatu daerah dapat diukur melalui pertumbuhan ekonomi perbedaan kinerja pembangunan disebabkan kemampuan daerah dalam upaya meningkatkan pertumbuhan ekonomi (Kuncoro \& Idris, 2015).

Tabel 4

Hasil Analisis Gabungan LQ Dan DLQ sektor pertanian antar provinsi di pulau Kalimantan

\begin{tabular}{|c|c|c|c|c|c|c|c|c|c|}
\hline $\begin{array}{c}\text { LQ \& } \\
\text { DLQ }\end{array}$ & $\begin{array}{l}\text { Pertanian, } \\
\text { kehutanan, } \\
\text { dan } \\
\text { perikanan }\end{array}$ & $\begin{array}{c}\text { Petanian, } \\
\text { peikanan, } \\
\text { perkebunan } \\
\text { dan jasa } \\
\text { pertanian }\end{array}$ & $\begin{array}{c}\text { Kehutanan } \\
\text { dan } \\
\text { penebangan } \\
\text { kayu }\end{array}$ & Perikanan & $\begin{array}{c}\text { Tanaman } \\
\text { pangan }\end{array}$ & $\begin{array}{c}\text { Tanaman } \\
\text { holtikultura }\end{array}$ & $\begin{array}{c}\text { Tanaman } \\
\text { perkebunan }\end{array}$ & Peternakan & $\begin{array}{c}\text { Jasa } \\
\text { pertanian } \\
\text { dan } \\
\text { pemburuan }\end{array}$ \\
\hline Kalbar & Tetap Basis & Tetap Basis & Tetap Basis & $\begin{array}{c}\text { Non Basis } \\
\text { menjadi } \\
\text { Basis } \\
\end{array}$ & $\begin{array}{l}\text { Tetap } \\
\text { Basis }\end{array}$ & Tetap Basis & Tetap Basis & Tetap Basis & Tetap Basis \\
\hline Kalteng & Tetap Basis & Tetap Basis & Tetap Basis & $\begin{array}{c}\text { Non Basis } \\
\text { menjadi } \\
\text { Basis }\end{array}$ & $\begin{array}{c}\text { Non } \\
\text { Basis } \\
\text { menjadi } \\
\text { Basis } \\
\end{array}$ & $\begin{array}{c}\text { Non Basis } \\
\text { menjadi } \\
\text { Basis }\end{array}$ & Tetap Basis & $\begin{array}{c}\text { Non Basis } \\
\text { menjadi } \\
\text { Basis }\end{array}$ & Tetap Basis \\
\hline Kalsel & Tetap Basis & Tetap Basis & $\begin{array}{c}\text { Non Basis } \\
\text { menjadi } \\
\text { Basis } \\
\end{array}$ & $\begin{array}{l}\text { Tetap } \\
\text { Basis }\end{array}$ & $\begin{array}{l}\text { Tetap } \\
\text { Basis }\end{array}$ & $\begin{array}{c}\text { Non Basis } \\
\text { menjadi } \\
\text { Basis } \\
\end{array}$ & Tetap Basis & $\begin{array}{c}\text { Non Basis } \\
\text { menjadi } \\
\text { Basis } \\
\end{array}$ & $\begin{array}{l}\text { Tetap Non } \\
\text { Basis }\end{array}$ \\
\hline Kaltim & $\begin{array}{c}\text { Tetap Non } \\
\text { Basis }\end{array}$ & $\begin{array}{l}\text { Tetap Non } \\
\text { Basis }\end{array}$ & Tetap Basis & $\begin{array}{c}\text { Non Basis } \\
\text { menjadi } \\
\text { Basis }\end{array}$ & $\begin{array}{c}\text { Non } \\
\text { Basis } \\
\text { menjadi } \\
\text { Basis } \\
\end{array}$ & $\begin{array}{c}\text { Non Basis } \\
\text { menjadi } \\
\text { Basis }\end{array}$ & $\begin{array}{c}\text { Non Basis } \\
\text { menjadi } \\
\text { Basis }\end{array}$ & $\begin{array}{c}\text { Non Basis } \\
\text { menjadi } \\
\text { Basis }\end{array}$ & $\begin{array}{c}\text { Non Basis } \\
\text { menjadi } \\
\text { Basis }\end{array}$ \\
\hline Kaltara & Tetap Basis & $\begin{array}{c}\text { Non Basis } \\
\text { menjadi } \\
\text { Basis }\end{array}$ & Tetap Basis & $\begin{array}{l}\text { Tetap } \\
\text { Basis }\end{array}$ & $\begin{array}{c}\text { Non } \\
\text { Basis } \\
\text { menjadi } \\
\text { Basis }\end{array}$ & Tetap Basis & $\begin{array}{c}\text { Non Basis } \\
\text { menjadi } \\
\text { Basis }\end{array}$ & $\begin{array}{c}\text { Non Basis } \\
\text { menjadi } \\
\text { Basis }\end{array}$ & $\begin{array}{c}\text { Non Basis } \\
\text { menjadi } \\
\text { Basis }\end{array}$ \\
\hline
\end{tabular}

Hasil analisis LQ dan DLQ berdasarkan menunjukkan pertanian tetap menjadi basis dengan nilai LQ lebih dari 1 nilai DLQ diatas nilai satu kecuali untuk provinsi Kalimantan timur yang basisi ekonominya berdasarkan sector pertambangan. pada sub sektor perikanan terdapat perbaikan kinerja nilai PDRBnya 
dengan meningkat dari non basis menjadi basis dan diharapkan hasil perikanan dari perikanan tangkap dan budidaya terus meningkat karena pemanfaatan ikan masih menggunakan teknologi yang belum maksimal menggunakan teknologi informasi dan pola pembudidayaan ikan yang terpadu. Subsector tanaman holtikultura diperlukan ditingkatkan transformasi ekomininya dengan berbagai upaya untuk meningkatkan partisipasi petani kecil di value chain digital market dengan edukasi kepada petani terkait upaya peningkatan kualitas produk, berproduksi secara konsisten dan peningkatan pengetahuan penggunaan teknologi digital. Upaya tersebut tentu saja memerlukan dukungan dari pihak ecommerce dan Pemerintah.

Sektor tanaman pangan perlu ditingkatkan Kembali dengan menerapkan teknologi pertanian yang terpadu dengan mekanisasi sehingga bisa dianikkan menjadi sector basis. Dan peningkatan kapasitas SDM pertanian dengan pelatihan dan magang bagi pemula petani tanaman pangan sehingga kedepannya regenerasi petani dapat diatasi. Sebagian besar petani memiliki akses yang terbatas terhadap irigasi sehingga membatasi upaya mereka untuk berproduksi sepanjang tahun. Upaya peningkatan kualitas juga terkendala dengan permodalan yang mereka miliki. Seperti yang kita ketahui, upaya peningkatan kualitas produk pertanian akan sangat tergantung dengan kualitas input pertanian yang digunakan oleh petani, misalnya bibit unggul, pupuk, obat-obatan.

Berbagai hambatan yang dihadapi oleh petani tersebut menimbulkan kekhawatiran di kalangan pengambil kebijakan dan peneliti, bahwa petani kecil hanya akan menjadi penonton terkait perkembangan pasar modern di negara mereka. Berbagai hambatan yang dihadapi petani kecil untuk berpartisipasi di pasar digital. Berdasarkan (Gs \& Rangga, 2017) mencatat, setidaknya terdapat dua hambatan utama yang dihadapi oleh petani kecil untuk masuk ke saluran pemasaran digital. Pertama, pemasaran digital mengharuskan petani untuk menguasai sejumlah keterampilan baru terkait teknologi digital, platform pembayaran online, keamanan siber dan lain-lain. Kedua, petani harus melakukan sejumlah investasi, yaitu paling tidak berupa kepemilikan smartphone dan akses internet. Adanya dua tantangan tersebut telah menimbulkan adanya kekhawatiran di kalangan peneliti dan pembuat kebijakan bahwa petani kecil sulit berpartisipasi dalam saluran pemasaran digital.

3. Analisis transformasi pertanian di pulau Kalimantan

Sektor pertanian yang selama ini menjadi sumber penghidupan masyarakat miskin pedesaan memiliki laju pertumbuhan sektoral yang lebih rendah dibandingkan sektor lainnya yaitu subsector tanaman pangan. Tumbuhnya sumsektor perkebunan sawit menjadi permasalahan pertumbuhan pembangunan ekonomi yang dicapai tidak dapat dinikmati oleh semua orang, hanya segelintir orang saja yang menikmatinya (Romli et al., 2016). Akibat transformasi yang tidak seimbang juga mempengaruhi kemiskinan.

fenomena aging farmer dan rendahnya pendidikan petani menjadi dua masalah yang melekat pada sektor pertanian (Yuniarti \& Sukarniati, 2021). Untuk itu perlu diketahui determinan yang mempengaruhi penambahan tenaga kerja di sektor pertanian. Kendala perlambatan percepatan transformasi sector pertanian akibat fenomena aging farmer yaitu meningkatkan harkat dan 
martabat sektor pertanian menjadi sektor yang menjanjikan lalui kebijakan yang pro terhadap petani dan memperbaiki akses pasar. Peningkatan dan perbaikan keterampilan, pengetahuan dan inovasi pertanian. dukungan dalam pembiayaan bagi petani berkaitan dengan tingkat keuntungan, risiko yang tinggi dan kepemilian agunan yang rendah menyebabkan penyaluran kredit terhadap sektor pertanian. Adanya subsidi bagi petani dan akses terhadap jasa keuangan. Adanya kebijakan mengurangi impor bahan pangan yang diproduksi di dalam negari, apalagi saat terjadi surplus. sosialisasi prospek ekonomi sektor pertanian yang efisien dan menguntungkan (Yuniarti \& Sukarniati, 2021).

Percepatan tranformasi ekonomi
sektor pertanian disebabkan
kemungkinan adanya ketidakefisienan dan ketidakefektifan pemerintah daerah dalam mengelola desentralisasi fiskal untuk mendorong perekonomian. Penyebab lainnya adalah karena terjadinya penurunan ekonomi global yang ditandai dengan perlambatan perekonomian global dan melemahnya harga komoditas seperti minyak bumi dan batu bara. Penurunan perekonomian global yang terjadi sangat berdampak pada menurunnya pendapatan Provinsi Kalimantan Timur. Bahkan alokasi untuk belanja modal lebih besar dibandingkan belanja lainnya seperti belanja pegawai, belanja barang dan jasa, dan belanja sosial. Namun, proporsi yang besar tersebut belum mampu guna memenuhi keperluan pangan penduduk. Kedepannya Perencanaan sektor pertanian dapat menarik minat kalangan pemuda dalam produski pertanian padi dan menghindarkan krisis tenaga pertanian muda (Subroto, 2020).
Dari sisi investasi, selama 20132020 tingkat penanaman modal di sektor pertanian, terutama pangan, hortikultura dan perternakan relatif sangat rendah. Nilai penanaman modal dari dalam negeri, sudah termasuk untuk sektor perkebunan yang terbesar. Tantangan kedepan investasi di sektor pertanian lebih berisiko dibandingkan dengan sektor jasa, serta memakan waktu jauh lebih lama untuk pengembalian modal. Sebenarnya, dengan pengelolaan yang baik, investasi di sub sektor hortikultura misalnya dapat memberikan pengembalian yang bersaing dengan penanaman modal di perkebunan atau non pertanian. Berdasarkan hasil penelitian di Provinsi Jambi (Nurhayani, 2019) investasi industri sektor primer berpengaruh secara nyata terhadap pertumbuhan ekonomi. Sedangkan investasi industri sektor sekunder dan tersier tidak berpengaruh secara nyata terhadap pertumbuhan ekonomi.

Pembangunan sektor pertanian dimasa yang akan datang perlu ditingkatkan dengan memaksimalkan pemanfaatan potensi yang dimiliki dengan meningkatkan kemampuan pengelolaan sektor pertanian antar Provinsi agar menghasilkan komoditi pertanian yang berdaya saing (Yulmardi \& Erfit, 2018). Pemerintah Daerah memperkuat struktur ekonomi dengan mengoptimalkan pengembangan komoditas unggulan, meningkatkan aktivitas industri pengolahan, dan daya tarik investasi. pembangunan di Kalimantan harus lebih diarahkan pada programmeningkatkan kinerja sektor pertanian peningkatan produktivitas, mutu, nilai tambah produk (value added), dan daya saing produk (competitiveness). pengembangan komoditas-komoditas yang memiliki peluang ekspor, investasi dan perdagangan; mengembangkan 
kawasan ekonomi terpadu ataupun kawasan ekonomi khusus yang didasarkan pada keterkaitan antar sektor dan kawasan sentra produksi. (Rustiadi et al., 2011) berpendapat bahwa roda perekonomian dapat bersinergi dengan baik Makin kuat keterkaitan antar sektor, makin kecil ketergantungan sektor tersebut pada impor, sekaligus memperkecil kebocoran wilayah yang mengalir ke wilayah lainnya, sehingga nilai tambah yang dihasilkan dapat dinikmati oleh masyarakat di wilayahnya sendiri.

\section{Kesimpulan}

Kontribusi subsektor pertanian pulau Kalimantan masih menjadi tumpuan kontribusi perekonomian daerah di pulau Kalimantan. sector pertanian masih tetap mempertahankan konribusi positif untuk menyumbang besaran sector primer di pulau kalimantan dengan tren pertumbuhan yang meningkat dengan peningkata kisaran $1 \%$. Dari penelitian ini telah terjadi transformasi pada dan bergeser peran subsektor kehutanan yang ditandai kontribusinya yang terus menurun. Transformasi ekonomi terjadi karena tidak semua di Pulau Kalimantan memiliki potensi sumberdaya alam yang melimpah menunjukkan transformasi dari sektor pertambangan dan penggalian ke sektor pertanian untuk propinsi kalimantan timur dan kalimantan selatan

Secara umum, selama periode 2013 2020 sektor unggulan yang ada di pulau Kalimantan diantaranya Sektor unggulan yang menjadi basis yaitu tanaman perkebunan, kehutanan dan penebangan kayu, subsektor perikanan, Tanaman Pangan, Peternakan, Tanaman Holtikultura.

\section{BIBLIOGRAFI}

Abidin, Z. (2015). Aplikasi Analisis Shift Share pada Transformasi Sektor
Pertanian dalam Perekonomian Wilayah di Sulawesi Tenggara. Jurnal Informatika Pertanian, 24(2), 165178.Google Scholar

Alhowaish, A. K., Alsharikh, M. A., Alasmail, M. A., \& Alghamdi, Z. A. (2015). Location quotient technique and economy analysis of regions: Tabuk Province of Saudi Arabia as a case study. International Journal of Science and Research (IJSR), 4(12), 1756-1761. Google Scholar

Alston, J. M., \& Pardey, P. G. (2014). Agriculture in the global economy. Journal of Economic Perspectives, 28(1), 121-146. Google Scholar

Ardiansyah, F., Diartho, H. C., \& Lestari, E. K. (2020). Structural Transformation of Agriculture and Poverty in Indonesia. Wiga: Jurnal Penelitian Ilmu Ekonomi, 10(1), 1-12. Google Scholar

Arif, S., \& Helmi, A. (2021). Tantangan pangan Indonesia ditengah pandemic covid-19. Google Scholar

Briones, R., \& Felipe, J. (2013). Agriculture and structural transformation in developing Asia: review and outlook. Asian Development Bank Economics Working Paper Series, 363. Google Scholar

Budisusila, A. (2021). Transformasi Ekonomi Indonesia Pasca Pandemi Covid 19. Sanata Dharma University Press. Google Scholar

De Fretes, P. N. (2017). Analisis sektor unggulan (Lq), struktur ekonomi (Shift Share), dan proyeksi produk domestik regional bruto Provinsi Papua 2018. Develop, 1(2). Google Scholar

FAO, E. C. A. (2018). Regional overview of food security and nutrition. Addressing the Threat from Climate Variability and Extremes for Food Security and Nutrition. Food and Agriculture Organization of the United Nations 
(FAO) and United Nations Economic Cooperation for Africa (UNECA), Accra. Google Scholar

Fattah, S., \& Rahman, A. (2013). Analysis of regional economic development in the regency/municipality at South Sulawesi province in Indonesia. Journal of Economics and Sustainable Development, 4(1), 1-9. Google Scholar

Gs, S., \& Rangga, K. (2017). Implementasi Cyber Extension Dalam Pengembangan Sumberdaya Manusia Pertanian: Kendala Yang Dihadapi Di Provinsi Lampung. Google Scholar

Hasan, M., Alim, A. M. S., Alfiani, A. S. M., Sachrir, M. I., Shafar, M. R., Hanim, N. F., Gunawan, R., Arafah, S., \& Audia, S. R. (2020). Teori-Teori Pembangunan Ekonomi. Media Sains Indonesia. Google Scholar

Jhingan, M. L. (2016). Ekonomi pembangunan dan perencanaan. Google Scholar

Kuncoro, M., \& Idris, A. N. (2015). Mengapa Terjadi Growth Without Development Di Provinsi Kalimantan Timur? Jurnal Ekonomi Pembangunan: Kajian Masalah Ekonomi Dan Pembangunan, 11(2), 172-190. Google Scholar

Nurhayani, N. (2019). Analisis pengaruh investasi industri sektor primer, sektor sekunder dan sektor tersier terhadap pertumbuhan ekonomi di Provinsi Jambi. Jurnal Paradigma Ekonomika, 14(2), 77-82. Google Scholar

Pratiwi, M. C. Y. (2021). Analisis Ketimpangan Antarwilayah dan Pergeseran Struktur Ekonomi di Kalimantan. Jurnal Borneo Administrator, 17(1), 131-154. Google Scholar

Romli, M. S., Hutagaol, M. P., \& Priyarsono, D. S. (2016). Transformasi struktural: Faktor-faktor dan pengaruhnya terhadap disparitas pendapatan di Madura. Jurnal
Ekonomi Dan Kebijakan Pembangunan, 5(1), 25-44. Google Scholar

Rustiadi, E., Saefulhakim, S., \& Panuju, D. R. (2011). Perencanaan dan Pengembangan Wilayah. Cetakan Ketiga. Yayasan Pustaka Obor Indonesia. Google Scholar

Safriansyah, S. (2010). Laju Pertumbuhan dan Analisa Daya Saing Ekspor Unggulan di Propinsi Kalimantan Selatan. JEPE: Jurnal Ekonomi Pembangunan, 8(2), 327-344. Google Scholar

Subroto, A. (2020). The Conceptual Dynamic Model of Rural Development Towards Sustainable Self-Sufficiency (penulis: Athor Subroto (Penulis Pertama dan Koresponden) dan Vanda Ningrum). In Springer. Google Scholar

Sugiyono, D. (2013). Metode penelitian pendidikan pendekatan kuantitatif, kualitatif dan R\&D. Google Scholar

Tajuddin, T., Syarif, M., Natsir, M., \& Nur, S. (2020). Dampak Transformasi Struktur Ekonomi Indonesia Terhadap Mobilitas Pekerja Antar Sektor. Jpep (Jurnal Progres Ekonomi Pembangunan), 5(1). Google Scholar

Todaro, M. P., \& Smith, S. C. (2003a). Economic Development, eight edition. England: Pearson Education Limited. Google Scholar

Todaro, M. P., \& Smith, S. C. (2003b). Pembangunan Ekonomi: Di Dunia Ketiga, Jilid 1. Google Scholar

Yulmardi, Y., \& Erfit, E. (2018). Daya saing sektor pertanian dalam mendorong pembangunan pertanian di Provinsi Jambi. Jurnal Paradigma Ekonomika, 13(2), 65-76. Google Scholar

Yuniarti, D., \& Sukarniati, L. (2021). Penuaan Petani dan Determinan Penambahan Tenaga Kerja di Sektor Pertanian. AGRIEKONOMIKA, 10(1), 
38-50. Google Scholar

\section{Copyright holder :}

Amak Priyatna, Dewi Rahayu, Saipudin (2022)

\section{First publication right :}

Jurnal Syntax Transformation

This article is licensed under:

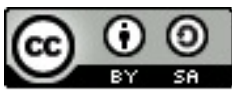

